\section{POST-WAR REHABILITATION AND RESETTLEMENT}

BY

\section{G. D. KERSLEY, M.D., F.R.C.P.}

Major, R.A.M.C.; Specialist in Physical Medicine

Rehabilitation, the complete range of treatment continued till the fullest working capacity is restored, has exercised many minds for many months. Numerous aspects have been dealt with by various authorities: the Army at the convalescent depots and selection centres, the R.A.F. at rehabilitation centres, the Ministry of Health at their rehabilitation departments at the main hospitals, the Ministry of Labour at their centre at Egham-where "pre-vocational guidance" is also involved-the Ministry of Pensions at Roehampton, the miners, the dock workers, and now even private enterprise backed by various industrial firms, are all engaged in tackling this problem in their own particular way. The field is vast, and includes not only the treatment of injuries and the scourge of rheumatism, but also planned convalescence, the prevention of breakdown in health, pre-vocational guidance so as to ensure correct placing of labour according to physique and mental fitness, vocational training, and provision of sheltered workshops. Yet, so far, co-ordination of these essentials of complete rehabilitation on a national basis is lacking. Below an attempt is made to outline the services necessary to carry out such a scheme.

The natural sequence of rehabilitation may be shown diagrammatically thus:

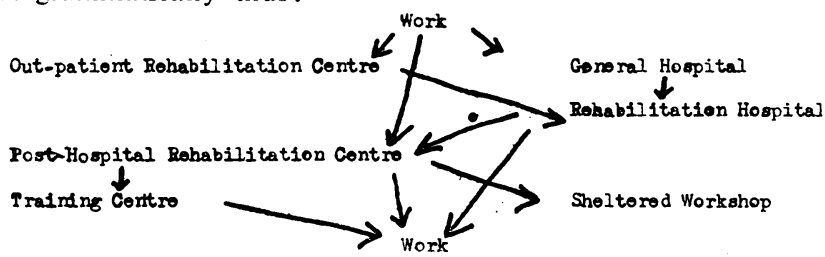

An Out-patient Rehabilitation Centre-the medical equivalent of a fracture A unit, with which it could be combined-would provide out-patient treatment and advice. It would be supervised, probably as a part-time appointment, by a medical officer who had had some special training in rehabilitation methods, and it would be visited regularly by one or more consultants. Rheumatic and orthopaedic cases requiring specialized and institutional treatment could be sent from here to a rehabilitation hospital.

General Hospitals would refer cases requiring long-term orthopaedic or rheumatic treatment to rehabilitation hospitals or hospital groups, while those patients requiring planned convalescence would be sent to a post-hospital rehabilitation centre. Each hospital of any size, however, will require its own physiotherapy and diversional occupation departments, and to co-ordinate these and to ensure that active treatment is started at the earliest possible moment a rehabilitation officer will also be necessary. The latter appointment would usually be held by a physician or surgeon already on the hospital staff.

The Rehabilitation Hospital or hospital group would receive patients from out-patient rehabilitation centres, fracture $B$ and $C$ centres, and general hospitals. It would consist of one or more hospitals-rheumatic, orthopaedic, and any with fracture A departments-and would have communal amenities in the form of a physiotherapy department, a gymnasium, a heated indoor swimming-pool, occupational therapy workshops, an $x$-ray department, and a laboratory. It should be situated within easy reach of an industrial area, but in open country, and it should maintain a very close link with the nearest medical teaching school and university in order to facilitate and co-ordinate teaching and research. Four of our largest spas-Bath, Buxton, Droitwich, and Harrogate-could, with a little expansion, easily fulfil these conditions for their surrounding areas, but they would no longer be watermongers. . A widespread movement in this, the right direction, was exemplified when recently the chairman of a spa committee announced that his spa's policy was to do all in its power to make it a useful $\operatorname{cog}$ in the wheel of the rehabilitation machine, and only to use the waters-applied according to the laws of orthodox physics-as one part of the facilities available to the medical team. The spa rheumatic hospitals would then act as the rehabilitation nuclei for their localities-Bath for Bristol and South Wales, Buxton for Manchester and Sheffield, Droitwich for Birmingham, and Harrogate for Leeds and Bradford. A senior medical or surgical qualification would have to be a sine qua non for their senior staff appointments-a regulation already introduced at one of these hospitals-and a closer liaison with the dean and professors of medicine and surgery of their associated universities would be required. A fourfold plan of co-operation between each spa hospital and its neighbouring university should be considered: (a) the use of the spa hospital for both postgraduate and antegraduate clinical teaching; $(b)$ the reference of cases requiring specialized institutional treatment and investigation to the spa hospital from the hospitals to which the university medical schools are attached; $(c)$ co-operation over special research; and $(d)$ a closer staff liaison, including the possibility of the professor of medicine becoming an honorary member of the Hospitals Medical Board and of certain beds being made available to the medical unit of the university. It is hoped that research, in addition to being linked with the university, will also be co-ordinated with that undertaken elsewhere, through a central body such as the Empire Rheumatism Council or an appropriate committee of the British Orthopaedic Association.

As regards the internal administration of such a rehabilitation hospital, co-ordination by a rehabilitation officer would be necessary. Individual treatment such as physiotherapy and -specific occupational therapy would be prescribed by the medical officer in charge of the case, who would also place the patient in a grade. Each grade would then have its organized programme of general exercise and diversional occupation or employment, and the technicians would refer to the doctor in charge of the case, by a system of slips via the rehabilitation officer, any remarks on the reaction to treatment and suggestions about alterations or regrading of the patient. Additional privileges in the way of late passes, etc., for the higher grades would act as an incentive to progress.

The Post-hospital Rehabilitation Centre would take the place of the convalescent depot in the Army, with the difference that it would have to deal with women as well as men, would take all age groups, and, instead of a hardening programme, diversional instruction and occupation and pre-vocational selection would be substituted. This centre would take patients from the rehabilitation and general hospitals and also direct from work when it was felt that a period of rest, build-up, and possibly change in occupation would avoid a breakdown. It should primarily be a medical unit, but every effort should be made to get away from the hospital atmosphere. An important entity would be a welfare department, which would follow up the progress of the individual in the occupational workshops with a view to replacement, or retraining where it eventually proved necessary. While at this centre many might be able to continue study or training in their own jobs or do some useful work, for which they should receive remuneration. The running of short courses for industrial medical officers, almoners, factory managers, and social workers would be another function of such a centre. On discharge men would return direct to work, to a Ministry of Labour training establishment, or to sheltered workshops.

The Tomlinson report made three main recommendations with regard to -resettlement: that employers must accept a fixed quota of the partially disabled, that these disabled persons should be registered, and that certain occupations should be scheduled especially for employment of such "handicapped persons." This has been criticized (Lancet, 1943, 2, 771) in so far that it is felt that a large proportion of the disabled could fend for themselves on the open market if employers were educated as to their use and value, and if both the worker-and the employer were protected from financial risk should it be found later that the handicapped person could not "cope," or if there should be some increase in the old disability or the onset of a new one. The cessation of all sick benefit as soon as any light work is undertaken and the liability of a firm employing a handicapped man, perhaps more prone to accident than normal, both militate against any voluntary solution to the problem of employment of the disabled. Yet a circular from the United States Office of Education showed that $98 \%$ of firms employing partially disabled persons found that, when suitably placed, such employees were actually more reliable than their fit co-workers.

Moreover, from another angle the financial security of the individual cannot be disregarded in considering the problem of rehabilitation. Undecided compensation is the greatest single cause of delay in return to work, owing to its psychological effect. If, however, financial security is safeguarded, it is felt that comparatively few could not find a suitable post when aided by suitable pre-vocational guidance and, if necessary, by vocational training. For the few failures, sheltered workshops or communities are, however, necessary. These will require extension in number and scope, and should include facilities for employing the chronic rheumatic in addition to those for the tuberculous, the injured, and the blind.

H. D. Pasachoff, M. J. Madonick, and C. Drayer (Amer. J. Dis. Child., 1944, 67, 201) record cases of four siblings showing the characteristic features of Marfan's disease or arachnodactyly. Two showed mental retardation. Air encephalography revealed definite internal hydrocephalus in one and some dilatation of the ventricular system in the other. The father and paternal grandfather showed elements of the disease. 